\title{
Suplementação de vacas leiteiras com homeopatia: desempenho e digestibilidade
}

[Supplementation of dairy cows with homeopathy: performance and digestibility]

\author{
J.R.M. Silva ${ }^{1}$, L.L. Bitencourt ${ }^{2}$, B.M.L. Oliveira ${ }^{3}$, G.S. Dias Júnior ${ }^{4}$, F. Lopes ${ }^{5}$, \\ R.A.N. Pereira ${ }^{6}$, M.N. Pereira ${ }^{4} *$
}
${ }^{1}$ Instituto Federal de Educação - Ciência e Tecnologia do Norte de Minas Gerais - Campus Januária - Januária, MG
${ }^{2}$ Instituto Federal de Educação - Ciência e Tecnologia do Espírito Santo - Campus Itapina - Colatina, ES
${ }^{3}$ Universidade Presidente Antônio Carlos - Departamento de Veterinária - Juiz de Fora, MG
${ }^{4}$ Universidade Federal de Lavras - Departamento de Zootecnia
Caixa Postal 3037 - 37200-000 - Lavras, MG
${ }^{5}$ University of Wisconsin - Department of Dairy Science - Madison, EUA
${ }^{6}$ Empresa de Pesquisa Agropecuária de Minas Gerais - Unidade Regional EPAMIG Sul de Minas - Lavras, MG

\section{RESUMO}

Avaliou-se o efeito da suplementação de uma combinação homeopática sobre o desempenho e a digestibilidade de nutrientes em vacas leiteiras. Trinta e duas vacas Holandesas foram blocadas em pares e aleatoriamente alocadas a um de dois tratamentos por 63 dias, posterior a um período de padronização de 14 dias. Variáveis mensuradas no final da padronização ajustaram medidas semanais da mesma variável no modelo de análise estatística. Os tratamentos foram: Suplementação diária com 150 gramas de uma combinação homeopática (Hypothalamus, $10^{-30}$; Colibacilinum, 10 ${ }^{-30}$; Streptococus Beta Hemolyticum, 10 $0^{-60}$; Streptococus Uberis, 10 ${ }^{-60}$; Phytolacca, 10 ${ }^{-60}$; Calcium Phosphoricum, 10 ${ }^{-30}$; Natrum Muriaticum, $10^{-60}$; Urtica Urens, $10^{-30}$; Silicea Terra, $10^{-400}$ ) em veículo mineral, ou 150 gramas do mesmo veículo mineral (controle). A suplementação com homeopatia aumentou o teor de proteína no leite de 3,09 para 3,19\% $(P=0,01)$ e tendeu a aumentar a secreção diária de proteína de 0,737 para $0,776 \mathrm{~kg}(P=0,10)$. A queda na digestibilidade da fibra e da matéria orgânica $(P=0,10)$, e a similaridade na relação entre alantoína e creatinina na urina $(P=0,32)$, sugerem que houve aumento na eficiência de síntese de proteína microbiana no rúmen. Apesar de o mecanismo não ter sido elucidado, a combinação homeopática aumentou o teor de proteína do leite.

Palavras-chave: gado de leite, proteína no leite, sólidos no leite, combinação homeopática

\begin{abstract}
The effect of supplementing a homeopathic combination on dairy cow performance and nutrient digestibility was evaluated. Thirty-two Holstein cows were paired blocked and randomly assigned to one of two treatments for 63 days, following a 14-day standardization period. Variables measured at the end of the standardization period adjusted weekly measurements of the same variable in the statistical analysis model. Treatments were: Daily supplementation of 150 grams of a homeopathic combination (Hypothalamus, $10^{-30}$; Colibacilinum, 10${ }^{30}$; Streptococcus Beta Hemolyticum, 10 $10^{-60}$, Streptococcus Uberis, $10^{-60}$; Phytolacca, $10^{-60}$; Calcium

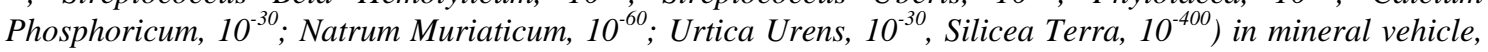
or 150 grams of the same mineral vehicle (Control). Supplementation with homeopathy increased milk protein content from 3.09 to $3.19 \%(P=0.01)$ and tended to increase the daily secretion of protein from 0.737 to $0.776 \mathrm{~kg}(P=0.10)$. The trend for decreased fiber and organic matter digestibilities $(P=0.10)$, and the similar allantoin to creatinine ratio in urine $(P=0.32)$, suggests that there was an increase in the efficiency of microbial protein synthesis in the rumen. Although the mechanism could not be elucidated, the homeopathic combination increased milk protein content.
\end{abstract}

Keywords: dairy cattle, milk protein, milk solids, homeopathic combination

Recebido em 19 de fevereiro de 2010

Aceito em 6 de abril de 2011

*Autor para correspondência (corresponding author)

E-mail: mpereira@dzo.ufla.br 


\section{INTRODUÇÃO}

A capacidade de substâncias muito diluídas em veículo inerte e agitadas a cada nova diluição (Davenas et al., 1988) de atuar sobre os sintomas de doenças humanas foi formalmente proposta como tecnologia alternativa às práticas médicas vigentes no final do século XVIII e início do século XIX (Hahnemann, 1810). Por esta teoria, a doença seria o resultado de algo virtual atuando sobre a porção imaterial dos organismos vivos (Hahneman, 1842; Aforisma 11; rodapé 2). Entretanto, na homeopatia não se objetiva explicar o mecanismo fisiológico de ação dos medicamentos sobre indivíduos (Hahnemann, 1810; Aforisma 28).

O uso veterinário da homeopatia vem de longa data (Boeriche, 1874) e é de alto interesse atual (Krutzinna et al., 1996; Vaarst et al., 2006) como alternativa a medicamentos convencionais, sendo coerente à tendência naturalista dos consumidores de alimentos de origem animal. Fatores normalmente utilizados para justificar o uso são: baixo custo, suposta inofensividade do tratamento e possibilidade de obtenção de produtos isentos de resíduos quimioterápicos, sem a necessidade de respeitar períodos de carência, e como alternativa em doenças em que as opções convencionais não foram efetivas.

Além do tradicional uso terapêutico, produtos homeopáticos têm sido comercializados no Brasil como promotores da produtividade de rebanhos leiteiros (Brasil, 1999). Nestes casos, normalmente são preconizadas combinações homeopáticas, de uso comum na terapêutica homeopática em vendas sem receita médica ou em epidemias (Jacobs et al., 2006; Jacobs et al., 2007). Uma combinação de homeopatias foi efetiva quando utilizada como procedimento padronizado na clínica veterinária (Elliott, 2001). Entretanto, o uso de combinações homeopáticas com o intuito de promover preventivamente a saúde e a fertilidade de vacas leiteiras não induziu resposta positiva (Fidelak et al., 2007). Homeopatias, tanto quanto outros fármacos, devem ter sua efetividade e seguridade comprovadas cientificamente (Frobish e Van Houweling, 1978).

O objetivo deste experimento foi avaliar a resposta em produção e eficiência alimentar de vacas leiteiras suplementadas continuamente com uma combinação homeopática comercial, bem como avaliar se eventos digestivos seriam um mecanismo plausível na resposta ao tratamento.

\section{MATERIAL E MÉTODOS}

Trinta e duas vacas da raça Holandesa, com 164£90,6 (média $\pm D P)$ dias em lactação no início do experimento, receberam uma dieta de padronização por 14 dias. Medidas de cada variável-resposta, obtidas entre os dias oito e 14 do período de padronização, foram utilizadas como covariável no modelo de análise estatística. Ao final da padronização, as vacas formaram 16 blocos de dois animais com base na produção diária de leite e foram aleatoriamente alocadas, dentro de bloco, a um de dois tratamentos por 63 dias do período de comparação. Algumas variáveis foram amostradas ao longo da comparação, caracterizando um delineamento em blocos ao acaso, ajustado para covariável, e com estrutura de medidas repetidas no tempo.

Os tratamentos foram: Homeopatia - 150 gramas da combinação homeopática (Hypothalamus, 10 30; Colibacilinum, $10^{-30}$; Streptococus Beta Hemolyticum, 10-60; Streptococus Uberis, 10 $0^{-60}$; Phytolacca, $10^{-60}$; Calcium Phosphoricum, 10 $0^{-30}$; Natrum Muriaticum, $10^{-60}$; Urtica Urens, $10^{-30}$; Silicea Terra, $\left.10^{-400}\right)$ em veículo mineral $(37,3 \%$ de $\mathrm{Ca} ; 0,04 \%$ de P; 15579ppm de Mg; 260ppm de $\mathrm{Mn} ;$ 4058ppm de Zn; 2294ppm de Fe; $1135 \mathrm{ppm}$ de $\mathrm{Cu}$; 96ppm de Co) (Convert $\mathrm{H}$ Leite ${ }^{\circledR}$. Real H Nutrição e Saúde Animal, Campo Grande, MT) ou Controle - 150 gramas de veículo mineral $(36,9 \%$ de $\mathrm{Ca} ; 0,07 \%$ de $\mathrm{P}$; 15899ppm de Mg; 204ppm de Mn; 4126ppm de Zn; 2908ppm de Fe; 1080ppm de Cu; 106ppm de Co). Os tratamentos foram administrados uma vez ao dia sobre o alimento fornecido pela manhã. Os animais foram alimentados individualmente, em confinamento total, com camas de areia e ordenhados duas vezes por dia.

As dietas completas (Tab. 1) foram misturadas duas vezes ao dia e oferecidas em quantidade suficiente para resultar em, no mínimo, 10\% do oferecido como sobra diária. A proporção de silagem de milho nas dietas foi ajustada duas vezes por semana de acordo com a variação no seu teor de matéria seca (MS). A quantidade de dieta oferecida e as sobras alimentares de cada vaca foram mensuradas diariamente. $\mathrm{Na}$ última 
semana da padronização e ao longo do período de comparação, amostras da silagem de milho, de cada ingrediente concentrado e das sobras alimentares de cada vaca foram coletadas diariamente e congeladas. Semanalmente, uma amostra composta de cada ingrediente foi formada com base em quantidades idênticas de matéria natural. Estas amostras compostas foram pré-secas em estufa ventilada por 72 horas a $55^{\circ} \mathrm{C}$, trituradas em peneira de $1 \mathrm{~mm}$ em moinho do tipo Thomas-Willey, e uma alíquota foi desidratada a $100^{\circ} \mathrm{C}$ por 24 horas para determinação do teor de MS. O consumo de matéria seca (CMS) foi calculado semanalmente pela diferença entre a soma dos oferecidos diários de matéria seca de cada alimento e a sobra diária de MS de cada animal.

Ao final do experimento, uma amostra representando os compostos semanais de cada ingrediente pré-seco foi formada com base na proporção do consumido de MS em cada semana experimental. Uma amostra composta das sobras semanais pré-secas de cada vaca também foi formada. Os teores de proteína bruta $(\mathrm{PB})$, fibra em detergente neutro (FDN), cinzas, e extrato etéreo (EE) foram, então, analisados. A PB foi analisada por um destilador a vapor do tipo Microkjeldhal (Official..., 1975). As análises de $\mathrm{EE}$ foram realizadas segundo o AOAC (Official..., 1990). As cinzas foram determinadas por incineração da amostra a $550^{\circ} \mathrm{C}$ por oito horas. $\mathrm{O}$ teor de FDN foi determinado por um ANKON $^{\circledR}$ Fiber Analyser (ANKON Technology Corporation, Fairport, EUA). A composição em nutrientes das dietas foi calculada dividindo-se o consumo de cada nutriente pelo consumo de matéria seca ao longo do experimento.

Tabela 1. Composição das dietas oferecidas em ingredientes e das dietas consumidas em nutrientes nos tratamentos homeopatia ou controle

\begin{tabular}{|c|c|c|}
\hline \multirow{2}{*}{ Ingredientes } & Homeopatia & Controle \\
\hline & \multicolumn{2}{|c|}{$\%$ da matéria seca } \\
\hline Silagem de milho & \multicolumn{2}{|c|}{45,0} \\
\hline Feno de tifton & \multicolumn{2}{|c|}{6,2} \\
\hline Farelo de soja & \multicolumn{2}{|c|}{14,0} \\
\hline Soja integral crua e quebrada & \multicolumn{2}{|c|}{4,1} \\
\hline Ureia & \multicolumn{2}{|c|}{0,5} \\
\hline Polpa de citros peletizada & \multicolumn{2}{|c|}{15,8} \\
\hline Milho maduro moído fino & \multicolumn{2}{|c|}{12,2} \\
\hline $\mathrm{NaCl}$ & \multicolumn{2}{|c|}{0,4} \\
\hline Minerais e vitaminas ${ }^{1}$ & \multicolumn{2}{|c|}{0,2} \\
\hline Bicarbonato de sódio & \multicolumn{2}{|c|}{0,9} \\
\hline Convert $\mathrm{H}$ leite ou veículo mineral & \multicolumn{2}{|c|}{0,7} \\
\hline \multicolumn{3}{|l|}{ Nutrientes } \\
\hline Proteína bruta $(\mathrm{PB})$ & 15,8 & 15,9 \\
\hline Fibra em detergente neutro (FDN) & 34,4 & 34,3 \\
\hline Fibra em detergente neutro oriunda de forragens & 26,4 & 26,3 \\
\hline Extrato etéreo (EE) & 5,4 & 5,4 \\
\hline Cinzas & 6,1 & 6,1 \\
\hline \multirow{2}{*}{ Carboidratos não fibrosos $(\mathrm{CNF})^{2}$} & 38,3 & 38,2 \\
\hline & \multicolumn{2}{|c|}{$\%$ da matéria natural } \\
\hline Matéria seca & 48,6 & 48,7 \\
\hline
\end{tabular}

${ }^{1}$ Minerais e vitaminas: 18,5\% de Ca; $15 \%$ de P; 3,0\% de Mg; 3,0\% de S; 240ppm de Co; 3000ppm de Cu; 8000ppm de Mn; 12000ppm de Zn; 90ppm de Se; 180ppm de I; $1.000 .000 U I / k g$ Vit. A; 250.000UI/kg Vit. D; 6.250UI/kg Vit E.

${ }^{2} \mathrm{CNF}=100-(\mathrm{PB}+\mathrm{FDN}+\mathrm{EE}+$ Cinzas $)$.

O leite de cada ordenha foi mensurado diariamente, e quatro ordenhas consecutivas foram amostradas nos dias seis e sete de cada semana para determinação dos teores de proteína, gordura, lactose e nitrogênio ureico. A produção diária de leite e sólidos de cada semana foi utilizada para comparar tratamentos. A secreção de energia no leite foi calculada pela 
equação: $[(0,0929 \times \%$ de gordura) $+(0,0547 \times$ $\%$ de proteína $)+(0,0395 \times \%$ de lactose $)] \times \mathrm{kg}$ de leite (Nutrient..., 2001).

O peso vivo foi mensurado após a ordenha da tarde nos dias 13 e 14 da padronização e a cada sete dias da comparação, iniciando no dia sete. O ganho diário de peso de cada vaca foi calculado pela inclinação da regressão linear ao longo do tempo dos pesos semanais. A condição corporal foi avaliada no final da padronização e nas semanas quatro e oito da comparação por observação visual em escala de 1 a 5 (Wildman et al., 1982). A condição corporal de cada vaca foi a média dentre os escores de três avaliadores independentes.

A digestibilidade aparente no trato digestivo total da MS (DMS), da matéria orgânica (DMO), da FDN (DFDN) e da matéria orgânica não-FDN (DMOnFDN) foi determinada por mensuração da produção fecal por coleta total de fezes realizada por oito horas ininterruptas nos dias 59, 60 e 61 da comparação. A coleta de fezes em cada dia foi iniciada com oito horas de atraso com relação ao dia anterior, visando obter uma amostragem representativa das 24 horas do dia, sem causar distúrbio no consumo de alimentos e na produção de leite dos animais. $\mathrm{O}$ consumo de matéria orgânica digestível (CMOD) foi calculado multiplicando-se o consumo de matéria orgânica mensurado semanalmente pela DMO mensurada na semana nove da comparação.

Três medidas de eficiência alimentar foram calculadas. A eficiência 1 foi definida como a produção diária de leite dividida pelo CMS; a eficiência 2, pela secreção diária de energia no leite dividida pelo CMS; a eficiência 3, pela secreção diária de energia no leite dividida pelo CMOD.

A relação entre as concentrações urinárias de alantoína e de creatinina foi mensurada para estimar diferenças relativas na produção de proteína microbiana no rúmen. Uma amostra de urina foi coletada no início e no final de cada um dos três períodos de oito horas de coleta total de fezes nos dias 59 a 61 . Ao volume de urina coletado foram adicionados $10 \%$ de ácido sulfúrico a $10 \%$, e a amostra acidificada foi armazenada a $4^{\circ} \mathrm{C}$. Uma amostra composta foi formada para cada vaca ao final dos três dias de coleta. Estas foram diluídas com água destilada na proporção 1:3 (urina:água) e congeladas a $-20^{\circ} \mathrm{C}$ até a realização das análises de alantoína e creatinina. Para a análise de alantoína, o procedimento adotado foi semelhante ao sugerido por Chen e Gomes (1995). Para a análise de creatinina, foi utilizado kit de análise laboratorial (Labtest Diagnóstica S.A., Lagoa Santa, Brasil, Cat. 35-100).

A atividade mastigatória foi mensurada no dia 62 da comparação, por observação visual da atividade bucal de cada animal a cada cinco minutos, durante um período contínuo de 24 horas. O tempo de mastigação foi definido como a soma dos tempos de ingestão de alimentos e de ruminação $\left(\operatorname{min~} \mathrm{d}^{-1}\right)$. Os tempos de mastigação, ingestão e ruminação por unidade de CMS foram calculados utilizando-se o CMS mensurado no dia da determinação da atividade mastigatória.

No dia 63, amostras de fluido ruminal foram coletadas por ruminocentese para determinação do $\mathrm{pH}$ e concentração de ácidos graxos voláteis (AGV). As amostras de fluido foram obtidas 12 horas \pm 44 minutos após o oferecimento matinal de alimentos, aleatoriamente dentro de bloco. $\mathrm{O}$ $\mathrm{pH}$ ruminal foi mensurado imediatamente. A amostra de fluido foi imediatamente congelada em nitrogênio líquido, e o teor de $\mathrm{AGV}$ foi analisado por cromatografia gás-líquida num cromatógrafo Varian CP-3800.

As variáveis medidas ao longo do tempo foram analisadas como medidas repetidas pelo procedimento Mixed do SAS (Statistical..., 1985) com modelo contendo o efeito contínuo de covariável (medida da mesma variável obtida no final do período de padronização) e os efeitos fixos de bloco (1 a 16), tratamento (homeopatia ou controle), semana (1 a 9) e interação entre tratamento e semana. A estrutura de covariância utilizada foi definida pelo critério de informação de Akaike, dentre autorregressiva de primeira ordem, não estruturada e simetria composta. O quadrado médio para o efeito de vaca dentro de tratamento foi utilizado como medida de erro para testar o efeito de tratamento. As variáveis de valor experimental único foram analisadas pelo procedimento GLM do Statistical... (1985), por modelo similar ao anterior, mas sem o efeito de semana, da interação deste fator com tratamento e sem a covariável. 


\section{RESULTADOS E DISCUSSÃO}

A composição e a quantidade de alimento consumido não diferiram entre tratamentos. Houve semelhança no CMS (Tab. 2), na composição em nutrientes das dietas consumidas (Tab. 1) e no comportamento ingestivo (Tab. 3). A resposta aos tratamentos ocorreu em um mesmo aporte de nutrientes e ingredientes dietéticos para os animais.

A suplementação com a combinação homeopática aumentou o teor de proteína no leite e tendeu a aumentar a produção diária de proteína (Tab. 2). O aumento induzido na secreção proteica pela glândula mamária foi agudo e perdurou pelas nove semanas da comparação (Fig. 1). Não foi detectado efeito de tratamento sobre outras medidas de desempenho animal (Tab. 2). A resposta altamente significativa em teor de proteína no leite $(P=0,01)$ evidencia a capacidade de substâncias muito diluídas em veículo inerte e, agitadas a cada nova diluição (Davenas et al., 1988), de atuar sobre organismos vivos.

Tabela 2. Desempenho e eficiência alimentar de vacas leiteiras suplementadas (homeopatia) ou não (controle) com homeopatia

\begin{tabular}{|c|c|c|c|c|c|c|}
\hline & Homeopatia & Controle & $\mathrm{EPM}^{1}$ & $P$ Trat $^{1}$ & $P$ Sem $^{1}$ & $P$ Int $^{1}$ \\
\hline \multicolumn{7}{|c|}{$\mathrm{kg} \mathrm{d}^{-1}$} \\
\hline Consumo de matéria seca & 18,1 & 18,1 & 0,26 & 0,93 & $<0,01$ & 0,56 \\
\hline Leite & 24,8 & 24,6 & 0,490 & 0,84 & $<0,01$ & 0,99 \\
\hline Gordura & 0,841 & 0,815 & 0,013 & 0,16 & $<0,01$ & 0,31 \\
\hline Proteína & 0,776 & 0,737 & 0,016 & 0,10 & $<0,01$ & 0,75 \\
\hline Lactose & 1,142 & 1,118 & 0,025 & 0,51 & $<0,01$ & 0,94 \\
\hline \multicolumn{7}{|c|}{$\%$} \\
\hline Gordura & 3,50 & 3,45 & 0,053 & 0,54 & $<0,01$ & 0,21 \\
\hline Proteína & 3,19 & 3,09 & 0,026 & 0,01 & $<0,01$ & 0,97 \\
\hline Lactose & 4,63 & 4,66 & 0,018 & 0,34 & $<0,01$ & 0,30 \\
\hline \multicolumn{7}{|c|}{$\mathrm{Kg}$} \\
\hline Peso vivo & 597 & 595 & 3,5 & 0,69 & $<0,01$ & 0,48 \\
\hline \multicolumn{7}{|c|}{$\mathrm{kg} \mathrm{d}^{-1}$} \\
\hline Ganho de peso & 0,300 & 0,321 & 0,072 & 0,84 & & \\
\hline \multicolumn{7}{|c|}{1 a 5} \\
\hline Condição corporal & 3,09 & 3,15 & 0,049 & 0,39 & $<0,01$ & 0,30 \\
\hline \multicolumn{7}{|c|}{$\mathrm{mg} \mathrm{dL}^{-1}$} \\
\hline $\mathrm{N}$ ureico no leite & 15,9 & 15,5 & 0,22 & 0,23 & $<0,01$ & 0,90 \\
\hline \multicolumn{7}{|c|}{ Mcal d $^{-1}$} \\
\hline Energia no leite & 16,7 & 16,4 & 0,31 & 0,53 & $<0,01$ & 0,55 \\
\hline Eficiência $1^{2}$ & 1,36 & 1,35 & 0,029 & 0,94 & $<0,01$ & 0,74 \\
\hline \multicolumn{7}{|c|}{ Mcal kg $^{-1}$} \\
\hline Eficiência $2^{2}$ & 0,92 & 0,90 & 0,012 & 0,43 & $<0,01$ & 0,42 \\
\hline Eficiência $3^{2}$ & 1,37 & 1,34 & 0,017 & 0,15 & $<0,01$ & 0,18 \\
\hline
\end{tabular}


Suplementação de vacas leiteiras...

Tabela 3. Atividade mastigatória de vacas leiteiras suplementadas (homeopatia) ou não (controle) com homeopatia

\begin{tabular}{|c|c|c|c|c|}
\hline & Homeopatia & Controle & $\mathrm{EPM}^{1}$ & $P_{\text {Trat }}{ }^{1}$ \\
\hline \multicolumn{5}{|c|}{$\operatorname{min~d}^{-1}$} \\
\hline Ruminação & 434 & 437 & 14,5 & 0,88 \\
\hline Ingestão & 272 & 269 & 13,1 & 0,89 \\
\hline Mastigação $^{2}$ & 705 & 706 & 20,7 & 0,98 \\
\hline Ingestão de água & 33 & 27 & 3,82 & 0,33 \\
\hline Primeira refeição & 64 & 67 & 4,92 & 0,62 \\
\hline \multicolumn{5}{|c|}{ min $\mathrm{kg}$ de consumo ${ }^{-1}$} \\
\hline Ruminação & 26,2 & 25,9 & 1,24 & 0,88 \\
\hline Ingestão & 16,5 & 15,9 & 0,91 & 0,66 \\
\hline Mastigação & 42,6 & 41,8 & 1,86 & 0,75 \\
\hline
\end{tabular}

${ }^{1} \mathrm{EPM}=$ erro padrão das médias. Valor de probabilidade para o efeito de Trat=tratamento.

${ }^{2}$ Mastigação=ruminação+ingestão.

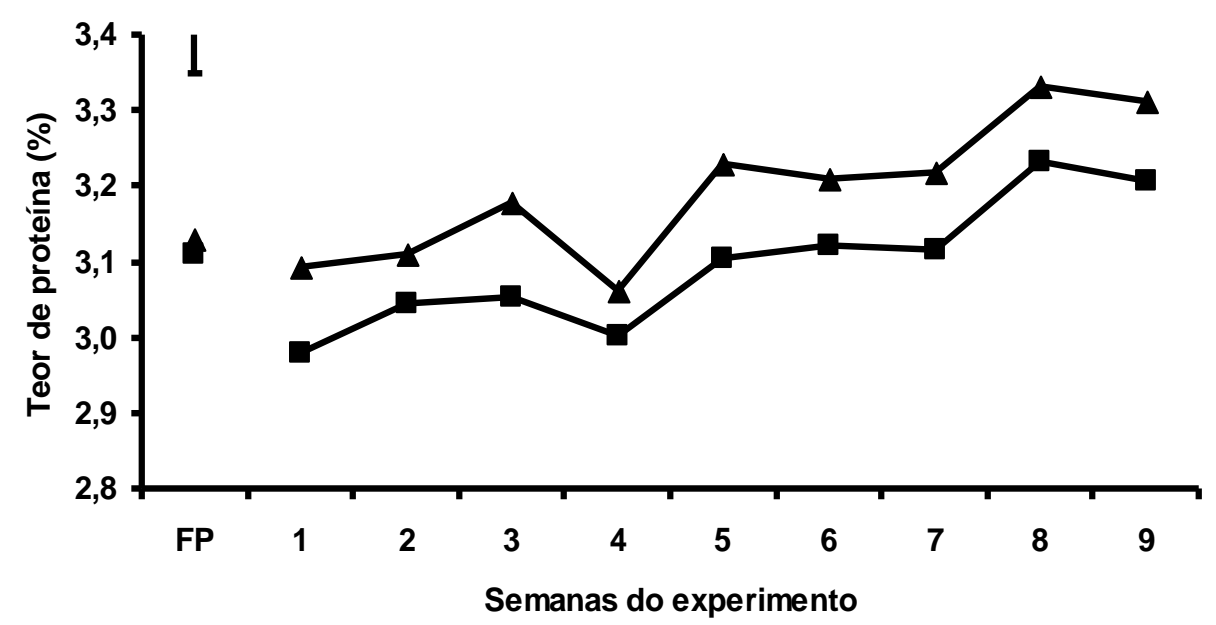

Figura 1. Teor de proteína no leite. Valores ajustados para a medida da mesma variável no final da padronização (FP). ( $\Delta$ ) Homeopatia. ( $\mathbf{a})$ Controle. $(P=0,01$ para o efeito de tratamento; $P<0,01$ para o efeito de semana; $P=0,97$ para a interação tratamento $v s$. semana).

A resposta positiva em secreção proteica ao tratamento homeopático sugere que uma condição comum a todos os animais era indutora de baixo teor de proteína no leite. Dietas formuladas por substituição total ou parcial de amido de milho por pectina e fibra de polpa cítrica, como a utilizada neste experimento (Tab. 1), podem deprimir a secreção proteica no leite (Solomon et al., 2000; Broderick et al., 2002; Salvador et al., 2008; Costa, 2008), por mecanismo que envolveu diferenças no metabolismo ruminal destes carboidratos (Paster e Canale-Parola, 1985; Hall e Herejk, 2001; Dusková e Marounek, 2001). Obter ganho em uma condição dietética capaz de induzir baixo teor de proteína no leite parece ter sido a ação prioritária da combinação homeopática.

Houve tendência de queda na DMO no tratamento homeopático. Entretanto, menor digestibilidade não foi acompanhada por queda na síntese ruminal de proteína microbiana, mensurada pela relação entre alantoína e creatinina na urina (Tab. 4). Um mecanismo pelo qual menor digestão resultaria em síntese proteica microbiana similar seria por aumento na taxa de passagem da digesta pelo rúmen, por resultar em ganho na eficiência de crescimento 
microbiano, por menor uso de energia para mantença pelos microrganismos (Isaacson et al., 1975). A possibilidade deste mecanismo também é suportada pela tendência de queda na DFDN, de menor valor, comparativamente à DMOnFDN (Tab. 4). Esta última, representativa da digestibilidade da proteína, lípides e carboidratos não fibrosos, todos nutrientes de alta digestibilidade, é sabidamente menos afetada que a DFDN pela velocidade de passagem da digesta pelo trato digestivo. O possível aumento na taxa de passagem da digesta pode ter reduzido a degradabilidade da proteína dietética no rúmen e ter aumentado o fluxo de aminoácidos metabolizáveis de origem dietética para o animal (Nutrient..., 2001). Esta seria uma explicação plausível para o aumento observado na secreção de proteína do leite.

Tabela 4. Consumo de matéria orgânica digestível, digestibilidade aparente de nutrientes no trato digestível total e relação entre a concentração urinária de alantoína e a de creatinina em vacas leiteiras suplementadas (homeopatia) ou não (controle) com homeopatia

\begin{tabular}{|c|c|c|c|c|c|c|}
\hline & Homeopatia & Controle & $\mathrm{EPM}^{1}$ & $P$ Trat $^{1}$ & $P$ Sem $^{1}$ & $P \operatorname{Int}^{1}$ \\
\hline \multicolumn{7}{|c|}{$\mathrm{kg} \mathrm{d}^{-1}$} \\
\hline $\mathrm{CMOD}^{2}$ & 12,4 & 12,6 & 0,19 & 0,62 & $<0,01$ & 0,50 \\
\hline \multicolumn{7}{|c|}{$\%$ do consumido } \\
\hline $\mathrm{DMS}^{2}$ & 66,4 & 68,5 & 1,04 & 0,18 & & \\
\hline $\mathrm{DMO}^{2}$ & 68,5 & 70,7 & 0,91 & 0,10 & & \\
\hline $\mathrm{DFDN}^{2}$ & 41,8 & 47,0 & 2,09 & 0,10 & & \\
\hline DMOnFDN $^{2}$ & 84,7 & 85,3 & 0,72 & 0,58 & & \\
\hline Alantoína/Creatinina & 2,3 & 2,6 & 0,21 & 0,32 & & \\
\hline
\end{tabular}

${ }^{1}$ EPM:=erro padrão das médias. Valor de probabilidade para os efeitos de Trat=tratamento; Sem=semana e Int=interação Trat $v s$. Sem.

${ }^{2} \mathrm{CMOD}=$ consumo de matéria orgânica digestível; $\mathrm{DMS}=$ digestibilidade da matéria seca; $\mathrm{DMO}=$ digestibilidade da matéria orgânica; DFDN=digestibilidade da fibra em detergente neutro; DMOnFDN=digestibilidade da matéria orgânica não-FDN.

Dentre as homeopatias presentes na combinação homeopática estudada, aquela com maior chance de ter acelerado a taxa de passagem da digesta pelo rúmen parece ser a Silicea Terra. Sabe-se que este produto, quando administrado em seres humanos com deficiência digestiva, melhora a assimilação de nutrientes, ou seja, induz ganho em digestibilidade (Boerick, 2009). No ser humano sadio, a Silicea causa cólica e retenção de fezes no reto, sugerindo exercer ação estimulatória sobre a motilidade de porções anteriores do trato digestivo. Esse modo de ação, atuando sobre a motilidade ruminal, seria capaz de acelerar a taxa de passagem da digesta e induzir queda na DMO e na DFDN (Tab. 4), em um mesmo nível de consumo de uma dieta (Tab. 2).

Neste caso, um distúrbio medicamentoso artificial pode ter sido induzido homeopaticamente em um animal nutricionalmente sadio (Hahnemann, 1833; Aforisma 29), tendo efeito positivo sobre a produção de proteína no leite. O distúrbio - uma doença induzida no animal são - pode ter atuado como cura da baixa secreção proteica comum ao grupo de animais. Considerando-se que medicamentos homeopáticos induziriam no indivíduo sadio os sintomas que curam no doente, estes dados sugerem que $\mathrm{pH}$ ruminal médio ao redor de 5,7 e relação entre acetato e propionato acima de 3,2 (Tab. 5) não foram representativos de falta de saúde digestiva. Tal fato é coerente à composição adequada da dieta oferecida em FDN efetivo e fisicamente efetivo (Armentano e Pereira, 1997) e à não ocorrência de alterações digestivas clínicas características de acidose ruminal (Enemark et al., 2002) durante a condução do experimento. A Silicea Terra pode ser uma ferramenta para induzir secreção proteica em vacas leiteiras alimentadas com dietas não excessivamente acidogênicas e, ao mesmo tempo, capazes de deprimir a síntese de proteína microbiana no rúmen. Obviamente que esta suposição requer validação por experimentação futura com o medicamento único. 
Suplementação de vacas leiteiras...

Tabela 5. Perfil de fermentação ruminal de vacas leiteiras suplementadas (homeopatia) ou não (controle) com homeopatia

\begin{tabular}{|c|c|c|c|c|}
\hline & Homeopatia & Controle & $\mathrm{EPM}^{1}$ & $P$ Trat $^{1}$ \\
\hline \multicolumn{5}{|c|}{$\mathrm{mM}$} \\
\hline Acetato & 103,7 & 102,1 & 5,69 & 0,84 \\
\hline Propionato & 32,7 & 31,2 & 1,90 & 0,59 \\
\hline Butirato & 18,4 & 17,8 & 1,07 & 0,65 \\
\hline $\mathrm{AGV}_{\text {total }}^{2}$ & 154,9 & 151,1 & 8,25 & 0,75 \\
\hline \multicolumn{5}{|c|}{$\%$ do AGV total } \\
\hline Acetato & 67,1 & 67,4 & 0,69 & 0,74 \\
\hline Propionato & 21,1 & 21,0 & 0,49 & 0,62 \\
\hline Butirato & 11,9 & 11,9 & 0,37 & 0,99 \\
\hline Acetato/propionato & 3,23 & 3,29 & 0,107 & 0,66 \\
\hline $\mathrm{pH}$ ruminal & 5,72 & 5,68 & 0,088 & 0,75 \\
\hline
\end{tabular}

${ }^{1}$ EPM=erro padrão das médias. Valor de probabilidade para o efeito de Trat=tratamento.

${ }^{2} \mathrm{AGV}$ total=acetato + propionato + butirato.

\section{CONCLUSÕES}

Apesar de o mecanismo da resposta não ter sido totalmente elucidado, foi evidenciada a capacidade da homeopatia de induzir resposta positiva em secreção proteica no leite de bovinos.

\section{REFERÊNCIAS BIBLIOGRÁFICAS}

ARMENTANO, L.E.; PEREIRA, M.N. Measuring the effectiveness of fiber by animal response trials. J. Dairy Sci., v.80, p.1416-1425, 1997.

BOERICHE, F.E. A manual of homeopathic veterinary practice. [s.1.]:[s.n.], 1874. 363 p.

BOERICK, O.E. Silicea terra. In: OSCAR, E. Boerick's repertory. 2009. Disponível em <http://www.webhomeopath.com/uk/materia_me dica.php?remedyid=1070>. Acessado em: $27 \mathrm{fev}$ 2009.

BRASIL. Ministério da Agricultura Pecuária e Desenvolvimento. Instrução Normativa $N^{\circ} 07$ de 17 de maio de 1999. Estabelece as normas de produção, tipificação, processamento, envase, distribuição, identificação e de certificação da qualidade para os produtos orgânicos de origem vegetal e animal. Diário Oficial da União. Brasília, 19 mai. 1999. Seção 1, p.11.
BRODERICK, G.A.; MERTENS, D.R.; SIMONS, R. Efficacy of carbohydrate sources for milk production by cows fed diets based on alfalfa silage. J. Dairy Sci., v.85, p.1767-1776, 2002.

CHEN, X.B.; GOMES, J. Estimation of microbial protein supply to sheep and cattle based on urinary excretion of purine derivatives: an overview of the technical details. Bucksburn Aberdeen, UK: International Feed Resources Unit. Rowett Research Institute, 1995. 20p.

COSTA, F.M.J. Resposta de vacas leiteiras alimentadas com polpa cítrica em substituição ao milho, à suplementação com metionina e à ensilagem de grãos de milho duro ou dentado. 2008. 122f. Tese (Doutorado em Zootecnia) Universidade Federal de Lavras, Lavras, MG.

DAVENAS, E.; BEAUVAIS, F.; AMARA, J. et al. Human basophil degranulation triggered by very dilute antiserum against IgE. Nature, v.333, p.816-818, 1988.

DUSKOVÁ, D.; MAROUNEK, M. Fermentation of pectin and glucose, and activity of pectin-degrading enzymes in the rumen bacterium Lachnospira multiparous. Lett. Appl. Microbiol., v. 33, p. 159-163, 2001.

ELLIOT, M. Cushing's disease: a new approach to therapy in equine and canine patients. $\mathrm{Br}$. Homeopath. J., v.90, p.33-36, 2001 
ENEMARK， J.M.D.; JORGENSEN， R.J.; ENEMARK, P.S. Rumen acidosis with special emphasis on diagnostic aspects of subclinical rumen acidosis: a review. Vet. Med. Zoot., v.20, p.16-29, 2002.

FIDELAK, C.; KLOCKE, P.; HEUWIESER, W. Homeopathic prophylaxis in dairy cows on an organic farm. Part 1 - Fertility. Dtsch. Tierarztl. Wochenschr, v.114, p.268-74, 2007.

FROBISH, R.A.; VAN HOUWELING, C.D. Clearance procedures for new animal drugs and feed additives. J. Dairy Sci., v.61, p.660-664, 1978

HAHNEMANN, C.F.S. Organon of Medicine. 1.ed. Leipzig. Alemanha, 1810. Disponível em: <http://www.homeopathyhome.com/reference/or ganon/organon.html>. Acessado em: $10 \mathrm{fev}$. 2009.

HAHNEMANN, C.F.S. Organon of Medicine. 5.ed. Kothen. Alemanha, 1833. Disponível em: <http://www.homeopathyhome.com/reference/or ganon/organon.html>. Acessado em: 10 fev. 2009.

HAHNEMANN, C.F.S. Organon of Medicine. 6.ed. Kothen. Alemanha, 1842. Disponível em: <http://www.homeopathyhome.com/reference/or ganon/organon.html>. Acessado em: $10 \mathrm{fev}$ 2009.

HALL, M.B.; HEREJK, C. Differences in yields of microbial crude protein from in vitro fermentation of carbohydrates. J. Dairy Sci., v.84, p.2486-2493, 2001.

ISAACSON, H.R.; HINDS, F.C.; BRYANT, M.P. et al. Efficiency of energy utilization by mixed rumen bacteria in continuous culture. $J$. Dairy Sci., v.58, p.1645-1659, 1975.

JACOBS, J.; FERNANDEZ, E.A.; MERIZALDE, B. et al. The use of homeopathic combination remedy for dengue fever symptoms: a pilot RCT in Honduras. Homeopathy, v.96, p.22-26, 2007.

JACOBS, J.; GUTHRIE, B.L.; MONTES, G.A. et al. Homeopathic combination remedy in the treatment of acute childhood diarrhea in Honduras. J. Altern. Complement. Med., v.12, p.723-732, 2006.
KRUTZINNA, C.; BOEHNCKE, E.; HERRMANN, H.J. Organic milk production in Germany. Biol. Agric. Hortic., v.13, p.351-58, 1996.

NUTRIENT requirements of dairy cattle. 7.ed., rev. Washington, DC: National Academy, 2001. $381 \mathrm{p}$.

OFFICIAL methods of analysis. 12.ed. v.1, Washington, DC: AOAC, 1975. v.1, 1094 p.

OFFICIAL methods of analysis. Arlington, VA: AOAC, 1990. v.1, 1117 p.

PASTER, B.J.; CANALE-PAROLA, E. Treponema saccharophilum sp. nov., a large pectinolytic spirochete from the bovine rumen. Appl. Environ. Microbiol., v.50, p.212-219, 1985.

STATISTICAL analysis software user's guide: statistics. 5.ed. Cary: Institute SAS, 1985. 129p.

SALVADOR, C.S.; PEREIRA, M.N.; SANTOS, J.F. et al. Resposta de vacas leiteiras à substituição total de milho por polpa cítrica e à suplementação com microminerais orgânicos II: Desempenho e economia. Arq. Bras. Med. Vet. Zootec., v.60, p.1142-1149, 2008.

SOLOMON, R.; CHASE, L.E.; BENGHEDALIA, D. et al. The effect of nonstructural carbohydrate and addition of full fat extruded soybeans on the concentration of conjugates linoleic acid in the milk fat of dairy cows. $J$. Dairy Sci., v.83, p.1322-1329, 2000.

VAARST, M.; BENNEDSGAARD, T.W.; KLAAS, I. et al. Development and daily management of an explicit strategy of nonuse of antimicrobial drugs in twelve danish organic dairy herds. J .Dairy Sci., v.89, p.1842-1853, 2006.

WILDMAN, E.E.; JONES, G.M.; WAGNER, P.E. et al. A dairy cow body condition scoring system and its relationship to selected production characteristics. J. Dairy Sci., v.65, p.495-501, 1982. 